\title{
GERAÇÃO DE GOTAS A PARTIR DE TÉCNICA MICROFLUÍDICA PARA A PRODUÇÃO DE MICROPARTÍCULAS POLIMÉRICAS
}

\author{
A.P. D. PEREIRA ${ }^{1}$, C. C. SIPOLI ${ }^{1}$ e L. G. de LA TORRE ${ }^{1}$ \\ ${ }^{1}$ Universidade Estadual de Campinas, Faculdade de Engenharia Química \\ E-mail para contato: latorre@feq.unicamp.br
}

\begin{abstract}
RESUMO - Esse trabalho teve como objetivo o estudo do processo de geração de gotas em microfluídica para a produção de partículas poliméricas. A microfluídica é uma área que utiliza dispositivos capazes de processar pequenas quantidades de fluidos (gerando apenas regime laminar de escoamento), permitindo operações contínuas em uma única fase ou na formação de gotas (duas fases imiscíveis). $\mathrm{O}$ processo de geração de gotas em microfluídica é utilizado para a produção de partículas poliméricas. A partir do controle de vazões é possível modular a formação das gotas e também o tamanho das gotas formadas. Neste trabalho são discutidos os aspectos importantes na geração de gotas em sistemas microfluídicos e uma investigação do processo.
\end{abstract}

\section{INTRODUÇÃO}

\subsection{Sistemas microfluídicos para a formação de nanopartículas poliméricas a partir da geração de gotas}

A microfluídica é definida como um campo multidisciplinar em que quantidades pequenas de fluidos são processadas permitindo o controle de concentrações de diferentes moléculas no espaço e no tempo (Whitesides, 2006), explorando características hidrodinâmicas para organização de fluxos de fluidos como reagentes químicos, células, lipídeos, ácidos nucléicos (Draghiciu et al., 2010; Kurita et al., 2010; Reiner et al., 2010; Baek et al., 2011; Yamashita et al., 2011).

Nos processos de geração de gotas é importante considerar o conceito de emulsão. Emulsão é um sistemas coloidal metaestável (Bibette, J., Calderon, F. L. e Poulin, P., 1999), composto por dois líquidos imiscíveis, em que existe uma única fase contínua e uma fase imiscível dispersa (no formato de gotas) (Bibette, J, Calderon, F Leal e Poulin, P, 1999; Umbanhowar, Prasad e Weitz, 2000; Solvas e Demello, 2011).

O princípio da geração de gotas é normalmente utilizado em microfluídica para a formação de partículas poliméricas de (quitosana, alginato), investigando principalmente a injeção cruzada de uma corrente aquosa, contendo o biopolímero com duas correntes oleosas. O controle das vazões permite a formação de gotas aquosas na corrente oleosa (emulsificação) e em seguida, como segunda etapa, esta mistura é coletada em um reator contendo agente reticulante em fase aquosa, para permitir a reticulação. Este processo requer uma terceira etapa de remoção do óleo. 
A presença de surfactantes estabiliza a emulsão, evitando que ocorra formação de gotas coalescentes devido aos seus grupos com afinidades na interface entre as fases imiscíveis, diminuindo a tensão superficial que assegura a estabilidade a longo prazo desses sistemas (Bibette, J, Calderon, F Leal e Poulin, P, 1999). A presença desses surfactantes contribui para o fenômeno Ostwald Ripening - processo espontâneo que acontece quando a fase dispersa apresenta baixa solubilidade na fase contínua e pequenas gotas se difundem na direção das gostas maiores que se fundem entre elas, levando ao aumento do tamanho das gotas com o tempo e formando uma emulsão com gotas maiores. (Bibette, 1999, Baret, 2012, Taylor, 1998).

Com foco na produção de gotas, é necessário estudar parâmetros que podem influenciar a qualidade da mesma. O primeiro a ser levado em conta é a seleção dos materiais apropriados, devido a fato de que as paredes do canal deve estar corretamente molhada. Em geral, a fase contínua deve molhar o canal ao invés da fase dispersa, a fim de proporcionar a formação das gotículas. (Christopher and Anna, 2007,Solvas, 2011,Seemann, 2012). No caso de dispositivos produzidos com o polímero polidimetilsiloxano (PDMS), que apresenta características hidrofóbicas, apenas emulsões do tipo água em óleo podem ser formadas (Christopher and Anna, 2007). É necessário também que haja controle de pressão e vazão para formação da gota desejada, já que esses são parâmetros que influenciam no seu tamanho final.

O processo de formação de gotas em dispositivos microfluídicos apresenta de maneira geral em diversas áreas (química fundamental e aplicada, biologia dentre outras) muitas vantagens, pois as reações são miniaturizadas pela compartimentalização das reações nas gotas produzidas. A produção de gotas em microcanais apresenta também rápida mistura de reagentes, controle de tempo das reações, controle interfacial das propriedades e além disso sistetizar e transportar reagentes sólidos e produtos (Song, Chen, e Ismagilov, 2006).

Como exemplo da formação de micropartículas em sistemas microfluídicos, a quitosana vem sendo recentemente explorada. A quitosana (QUI) é um polissacarídeo biodegradável, hidrofílico, atóxico e biocompatível, obtido a partir da desacetilação alcalina da quitina (Lee et al., 2001), que é obtida do exoesqueleto de crustáceos. A quitosana é um copolímero e sua estrutura química é formada pelos monômeros beta - (1-4)-2-amino-2-desoxi-D-glicose e beta-(1-4)-2-acetamida-2-desoxi-D-glicose com presença de grupos amino e hidroxila em sua cadeia conforme a Figura 1 a seguir. É um polímero muito estudado para desenvolvimento em sistemas de carreamento de ácidos nucléicos para terapia gênica (Huang et al., 2005).

Figura 1: estrutura química da quitosana (SILVA, 2006). 

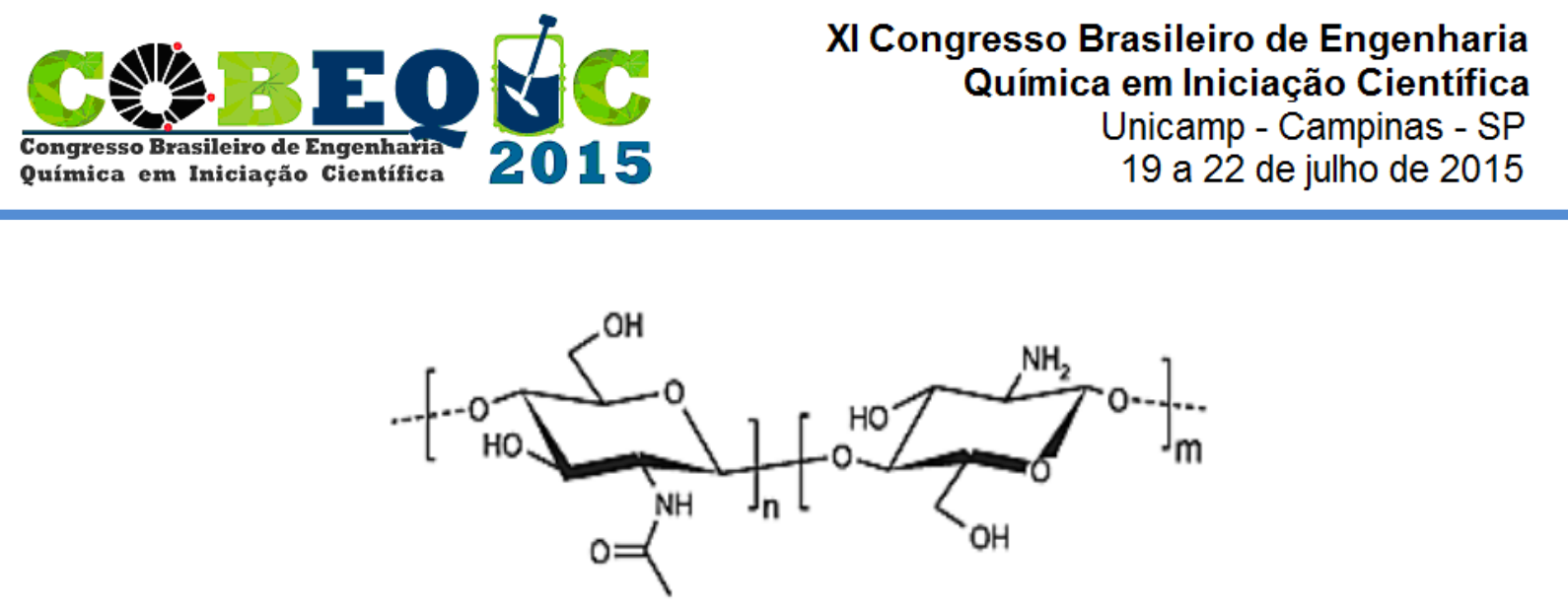

Uma alternativa à direta complexação do DNA com a QUI é a reticulação com Trifosfato pentasódico (TPP), que apresenta as seguintes vantagens: (i) a encapsulação física na matriz polimérica é mais estável e proporciona melhores características de liberação sustentada a gelificação ionotrópica permite a co-encapsulação de outras moléculas, tal como proteínas, para melhorar a internalização e o tráfego intracelular do DNA (FernandezUrrusuno et al., 1999; Csaba, Garcia-Fuentes e Alonso, 2009).

Nanopartículas de quitosana podem ser obtidas a partir de várias metodologias tais como: secagem por nebulização (spray drying) (Agnihotri, Mallikarjuna e Aminabhavi, 2004; Tewa-Tagne et al., 2007); reticulação por emulsão (Agnihotri, Mallikarjuna e Aminabhavi, 2004), coacervação/precipitação (Peniche et al., 2003; Agnihotri, Mallikarjuna e Aminabhavi, 2004; Tewa-Tagne et al., 2007), micelas reversas e gelificação iontrópica (Agnihotri, Mallikarjuna e Aminabhavi, 2004).

Recentemente, a focalização hidrodinâmica em fluxo contínuo e uma fase foi estudada para a formação de nanopartículas de quitosana e reticulada com adenosina trifosfato (ATP) (Majedi et al., 2012). Neste caso, uma corrente central contendo a quitosana foi fluidodinamicamente comprimida por duas correntes laterais aquosas contendo ATP, em dispositivo microfluídico. No entanto, a gelificação ionotrópica com ATP e a incorporação de ácidos nucleicos ainda não foram avaliadas em ensaios de transfecção, bem como o emprego desta técnica com TPP. Os autores obtiveram nanopartículas com tamanho na ordem de 100 $\mathrm{nm}$ índice de polidispersidade 0,2 , ou seja, 2 vezes menor do que as partículas que produziram pelo sistema convencional.

Nanopartículas auto-agregáveis formadas a partir de quitosana modificada quimicamente foram preparadas em dispositivo no formato T (Majedi et al., 2013). Neste caso, a variação do $\mathrm{pH}$ permite que esta molécula se auto-agregue (pH 7,4). Desta forma, os autores utilizaram um dispositivo baseado na focalização hidrodinâmica e que possuía na entrada central a fase aquosa contendo a quitosana hidrofobicamente modificada e nas outras duas entradas laterais utilizou-se água em $\mathrm{pH}$ básico. $\mathrm{O}$ tamanho e polidispersidade das nanopartículas foi da ordem de $100 \mathrm{~nm}$ e 0,2 , respectivamente.

Atualmente, um grande desafio tecnológico é a produção de micro e nanopartículas de poliméricas e mais especificamente de quitosana em sistemas microfluídicos.

\section{MATERIAIS E MÉTODOS}




\subsection{Materiais}

$\checkmark$ Quitosana de baixa massa molar (Sigma Aldrich);

$\checkmark$ Trifosfato pentasódico (TPP) (Sigma Aldrich);;

$\checkmark \quad$ Span 80 (Sigma Aldrich);

$\checkmark$ Óleo mineral (Sigma Aldrich);

$\checkmark$ Kit Sylgard 184 (Dow Corning).

\subsection{Métodos}

\subsection{Produção dos microdispositivos}

O primeiro passo para a produção dos microdispositivos que neste caso eram de PDMS (polímero utilizado na produção de dispositivos) e vidro é o desenho destes no programa AUTOCAD nas dimensões em que foram produzidos. $\mathrm{O}$ arquivo foi impresso em fotolito e usado como molde positivo para o processo de litografia macia.

Após a preparação da máscara utilizou-se o kit Sylgard 184 contendo o polímero poli(dimetilsiloxane) conhecido por PDMS e seu agente de cura. O polímero e seu agente de cura foram misturados em uma proporção de 10:1. Foi realizado o processo de desgaseificação da mistura em dessecador sob vácuo, para então ser vertido à máscara (contida em placa de petri). Depois de se verificar que não existia nenhuma bolha no polímero foi feito o processo de cura que pode ocorrer a temperatura ambiente overnight ou ser colocada em estufa a $80^{\circ} \mathrm{C}$ durante $1 \mathrm{~h}$. Após o processo de cura retirava-se o polímero da máscara. A Figura 3 apresenta uma descrição geral do processo de formação dos microdispositivos de PDMS.

Figura 3: Processo geral para a produção de dispositivos microfluídicos formados por PDMS (polidimetilsiloxano) Fonte de la Torre et al. 2014.

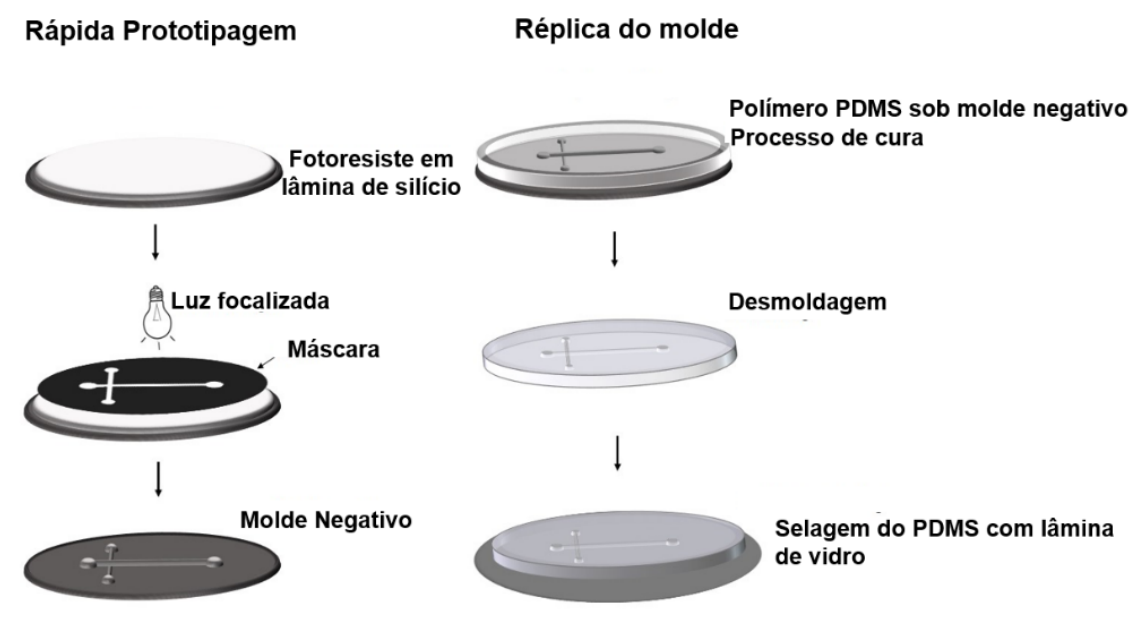


O polímero foi então retirado da máscara cortando-se com bisturi e em seguida, utilizando um microscópio e um dispositivo, utilizado na área médica para realizar biópsia, realizava-se a entrada e saída dos microcanais, permitindo o acoplamento das tubulações de entrada e saída do dispositivo.

O dispositivo tinha base de vidro, e uma lâmina de microscópio era utilizada para adesão da placa de PDMS. O método para a realizar a adesão foi o plasma. O procedimento consistia em colocar o dispositivo de PDMS e a lâmina de vidro em dessecador (contendo base de alumínio). O dessecador era mantido durante 1 minuto sob vácuo (bomba de vácuo). Em seguida, este sistema com vácuo era colocado em um microondas durante 7 segundos (30\% da potência máxima). Em seguida, retirando-se o vácuo, realizava-se a adesão do dispositivo de PDMS e da lâmina de vidro. O plasma realiza uma mudança nas superfícies de ambos os materiais e permite a adesão.

Uma foto do dispositivo produzido está na apresentada na Figura 4:

Figura 4: Foto do dispositivo PDMS/vidro.

\subsection{Estudo de vazões para formação de gotas para a produção de partículas poliméricas}

O projeto de formação gotas para produção de nanopartículas de quitosana foi baseado no modelo de dispositivo desenvolvido para a complexação entre lipossomas e ácidos nucleicos (Hsieh et al., 2009) (Figura 5). A fase aquosa flui pelo canal central a partir de duas entradas distintas (entrada de quitosana e de agente reticulante, separadamente) que se fundem formando um fluxo único. Este fluxo aquoso sofre um estreitamento pela injeção de correntes cruzadas de óleo mineral que geram uma tensão de cisalhamento e formam gotas aquosas dentro de um fluxo de óleo. O surfactante utilizado para estabilização das gotas é Span 80. Este modelo de dispostivo foi escolhido de maneira a promover melhor eficiência de mistura entre a quitosana e o agente reticulante.

Figura 5: Esquema do sistema microfluídico para a incorporação de ácidos nucleicos em lipossomas catiônicos e nanopartículas de quitosana, ampliando o local de estreitamenteo do microdispositivo onde ocorre a encapsulação dos complexos em gotas. Adaptado de HSIEH et al., 2009 


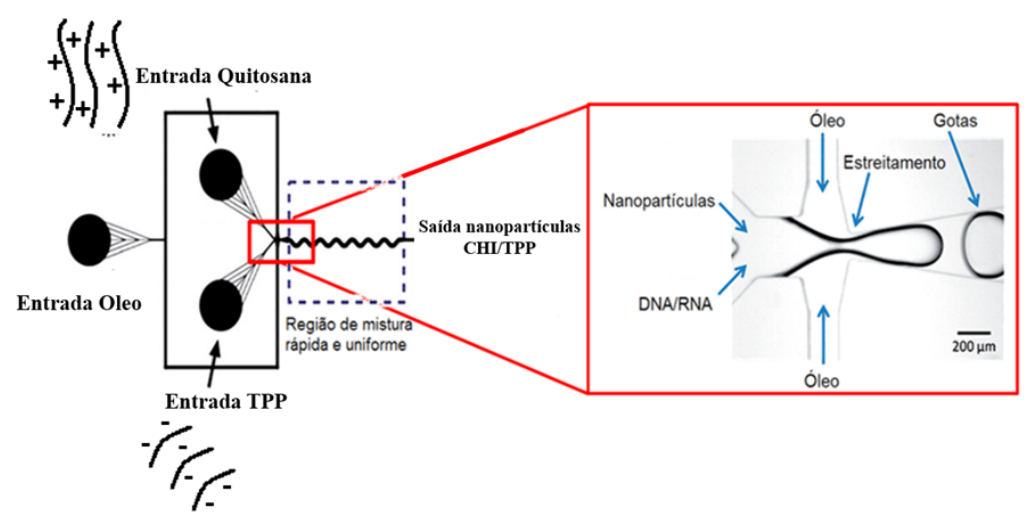

\section{RESULTADOS PRELIMINARES}

\subsection{Processo de formação de gotas para produção de partículas de poliméricas (quitosama)}

Este trabalho de iniciação científica iniciou-se em Janeiro de 2015 e está na etapa de estudo de vazões para obtenção de gotas contendo a fase aquosa com QUI e TPP como mostra a Figura 6 . Esta etapa é extremamente importante para estabilização das gotas formadas e assim garantir melhor homogeneidade na mistura dentro das gotas. A partir da coleta das amostras será realizada separação do óleo e da fase aquosa e assim a caracterização das nanopartículas de QUI/TPP a em termos de diâmetro hidrodinâmico, potencial zeta e polidispersidade e também morfologia das partículas obtidas.

Figura 6 - Estudo preliminar de obtenção de gotas a partir do processo microfluídico para produção de nano/micropartículas de QUI/TPP.

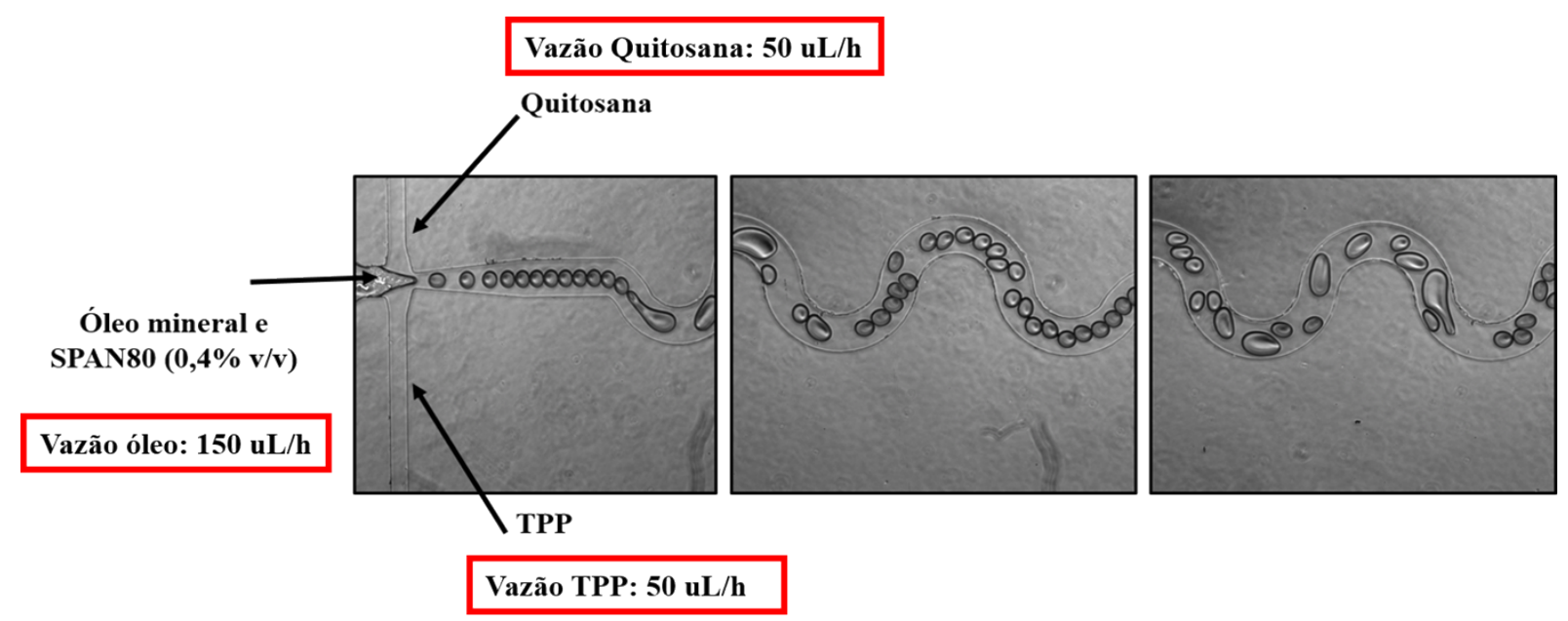


A etapa inicial deste trabalho teve ínicio em Janeiro deste ano com a construção dos dispositivos microfluídicos e por isso o estudo de vazão para formação de gotas ainda está sendo investigado..

A Figura 6 mostrada anteriormente apresenta a formação de gotas de quitosana e TPP. Neste condição a vazão do óleo foi de $150 \mathrm{uL} / \mathrm{h}$ e a vazão total da fase aquosa foi de 100 $\mathrm{uL} / \mathrm{h}$. Como é possível verificar na Figura 6 a formação de gotas é homogênea e é possível perceber uma mudança no formato a medida que passam pela serpentina do microcanal que foi desenhada para promover melhor mistura da quitosana com o TPP. Acredita-se que a formação das partículas ocorra de maneira compartimentalizada dentro das gotas e por isso apresentam baixa polidispersidade (estudos de caracterização das partículas serão feitos posteriormente).

\section{CONCLUSÕES}

O processo de formação de partículas poliméricas em dispositivos microfluídicos ainda deve ser muito investigado para se atingir condições de tamanho, polidispersidade desejáveis. No âmbito do processo de produção de partículas a partir da formação de gotas pouco se é discutido na literatura e por isso muitos parâmetros ainda precisam ser investigados, tais como: vazões das correntes aquosas e oleosas, concentração do polímero e do agente reticulante, estabelecimento do tipo e da concentração de surfactante, remoção do óleo, dentre outros.

A vazão estudada preliminarmente produziu gotas homogêneas. Estudos posteriores visam avaliar diferentes vazões e suas influências no tamanho de partículas obtidas.

\section{REFERÊNCIAS}

AGNIHOTRI, S. A.; MALLIKARJUNA, N. N.; AMINABHAVI, T. M. Recent advances on chitosan-based micro- and nanoparticles in drug delivery. Journal of Controlled Release, v. 100, n. 1, p. 5-28, 11/5/ 2004. ISSN 0168-3659. Disponível em: < http://www.sciencedirect.com/science/article/pii/S0168365904003803 $>$.

BAEK, J. et al. Investigation of Indium Phosphide Nanocrystal Synthesis Using a High-Temperature and High-Pressure Continuous Flow Microreactor. Angewandte Chemie-International Edition, v. 50, n. 3, p. 627-630, 2011 2011. ISSN 1433-7851. Disponível em: $<<$ Go to ISI $>: / /$ WOS:000286573700006 >.

BIBETTE, J.; CALDERON, F. L.; POULIN, P. Emulsions: basic principles. Reports on Progress in Physics, v. 62, n. 6, p. 969-1033, Jun 1999. ISSN 0034-4885. Disponível em: <<Go to ISI $>$ ://WOS:000080995800003 >.

BIBette, J.; CAlderon, F. L.; POUlin, P. Emulsions: basic principles. Reports on Progress in Physics, v. 62, n. 6, p. 969 , 1999. ISSN 0034-4885.

CSABA, N.; GARCIA-FUENTES, M.; ALONSO, M. J. Nanoparticles for nasal vaccination. Advanced Drug Delivery Reviews, v. 61, n. 2, p. 140-157, 2/27/ 2009. ISSN 0169-409X. Disponível em: $<$ http://www.sciencedirect.com/science/article/pii/S0169409X08002640 $>$.

De La Torre LG, Balbino TA, Sipoli CC, Vitor MT, Oliveira AF. Trends on Microfluidic Liposome Production through Hydrodynamic Flow-focusing and Microdroplet Techniques for Gene Delivery Applications. In: Finney L, Eds. Advances in Liposomes Research. New York: Nova Science Publishers; 2014: 63-96 
DRAGHICIU, L. et al. Manipulation of nanoparticles within a microfluidic system based on SU-8 polymer for bio-applications. Materials Science and Engineering B-Advanced Functional Solid-State Materials, v. 169, n. 1-3, p. 186-192, May 25 2010. ISSN 0921-5107. Disponível em: $<<$ Go to ISI $>$ ://WOS:000278588700034 >.

FERNANDEZ-URRUSUNO, R. et al. Development of a freeze-dried formulation of insulin-loaded chitosan nanoparticles intended for nasal administration. STP pharma sciences, v. 9, n. 5, p. 429-436, 1999. ISSN 1157-1489.

HSIEH, A. T.-H. et al. Nonviral gene vector formation in monodispersed picolitre incubator for consistent gene delivery. Lab on a Chip, v. 9, n. 18, p. 2638-2643, 2009.

HUANG, M. et al. Transfection efficiency of chitosan vectors: effect of polymer molecular weight and degree of deacetylation. Journal of Controlled Release, v. 106, n. 3, p. 391-406, 2005. ISSN 0168-3659.

KURITA, H. et al. Fluorescence observation and manipulation of individual DNA molecules in a microfluidic channel. MicroNanoMechatronics and Human Science (MHS), 2010 International Symposium on, 2010, 7-10 Nov. 2010. p.295-299.

LEE, S.-T. et al. Equilibrium and kinetic studies of copper(II) ion uptake by chitosan-tripolyphosphate chelating resin. Polymer, v. 42, n. 5, p. 1879-1892, 3// 2001. ISSN 0032-3861. Disponível em: < http://www.sciencedirect.com/science/article/pii/S003238610000402X >.

MAJEDI, F. S. et al. Microfluidic assisted self-assembly of chitosan based nanoparticles as drug delivery agents. Lab on a Chip, v. 13, n. 2, p. 204-207, 2013 2013. ISSN 1473-0197.

MAJEDI, F. S. et al. Microfluidic synthesis of chitosan-based nanoparticles for fuel cell applications. Chemical Communications, v. 48, n. 62, p. 7744-7746, 2012.

PENICHE, C. et al. Chitosan: an attractive biocompatible polymer for microencapsulation. Macromolecular Bioscience, v. 3, n. 10, p. 511520, 2003. ISSN 1616-5195.

REINER, J. E. et al. Accurate Optical Analysis of Single-Molecule Entrapment in Nanoscale Vesicles. Analytical Chemistry, v. 82, n. 1, p. 180-188, Jan 1 2010. ISSN 0003-2700. Disponível em: <<Go to ISI $>$ ://WOS:000273265700033 >.

SOLVAS, X. C. I.; DEMELLO, A. Droplet microfluidics: recent developments and future applications. Chemical Communications, v. 47 , n. 7, p. 1936-1942, 2011. ISSN 1359-7345. Disponível em: << Go to ISI $>$ ://WOS:000286766600001 >.

SONG, Helen; CHEN, Delai L.; ISMAGILOV, Rustem F. Reactions in droplets in microfluidic channels. Angewandte chemie international edition, v. 45, n. 44, p. 7336-7356, 2006.

TEWA-TAGNE, P. et al. Spray-drying Nanocapsules in Presence of Colloidal Silica as Drying Auxiliary Agent: Formulation and Process Variables Optimization Using Experimental Designs. Pharmaceutical Research, v. 24, n. 4, p. 650-661, 2007/04/01 2007. ISSN 0724-8741. Disponível em: $<$ http://dx.doi.org/10.1007/s11095-006-9182-3 $>$.

UMBANHOWAR, P.; PRASAD, V.; WEITZ, D. Monodisperse emulsion generation via drop break off in a coflowing stream. Langmuir, v. 16, n. 2, p. 347-351, 2000. ISSN 0743-7463.

YAMASHITA, T. et al. Cultivation and recovery of vascular endothelial cells in microchannels of a separable micro-chemical chip. Biomaterials, v. 32, n. 10, p. 2459-2465, Apr 2011. ISSN 0142-9612. Disponível em: <<Go to ISI>://WOS:000287627400002 >. 